\title{
Prescribing patterns of novel oral anticoagulants following regulatory approval for atrial fibrillation in Ontario, Canada: a population-based descriptive analysis
}

\author{
Yan Xu BSc, Anne M. Holbrook MD PharmD MSc, Christopher S. Simpson MD, \\ Dar Dowlatshahi MD PhD, Ana P. Johnson PhD
}

See related commentary in CMAJ by Coppens and colleagues at www.cmaj.ca/lookup/doi/10.1503/cmaj.131291.

Abstract

Background: The clinical armamentarium for anticoagulation has expanded substantially since the recent approval of dabigatran, rivaroxaban and apixaban for the prevention of stroke in atrial fibrillation. However, patients in the general population often differ from participants in clinical trials. In this study, we assessed the uptake of these novel oral anticoagulants in Ontario, Canada, within the first 2 years after dabigatran's approval for this indication.

Methods: Using data on province-wide prescription volumes, we conducted a time-series analysis of prescription trends between October 2010 and September 2012 for all orally administered anticoagulants (warfarin, dabigatran and rivaroxaban) that were available in this period. We stratified dabigatran prescription rates by age group (20-39, 40-59, 60-64, 65-84 and $\geq 85$ yr). We compared the proportion of dabigatran prescriptions to patients aged 65 or older with similar data from the Randomized Evaluation of LongTerm Anticoagulation Therapy (RE-LY) study.

Results: Over the 24-month study period, we found that prescriptions for the novel anticoagulants rose more than 20-fold, to represent $21.1 \%$ of all prescriptions of oral anticoagulants by September 2012 . The rise in prescriptions was due primarily to an increase in dabigatran use. Prescription rates of dabigatran were highest among people aged 85 years or more, a group at increased risk of bleeding who are markedly older than the average participant in the clinical trial in which the drug was tested (71 yr). In September 2012 , most of the dabigatran prescriptions were for the lower-dose formulation $(110 \mathrm{mg})$ in the older groups (58.8\% of dabigatran prescriptions in the 65-84 age group and $93.6 \%$ in the oldest group).

Interpretation: We observed rapid growth in the uptake of the novel oral anticoagulants since their approval for use in patients with atrial fibrillation, especially among those aged 85 years or more. This increase in use in the oldest group, a population at high risk of bleeding, signals the need to evaluate outcomes of use of novel oral anticoagulants in the clinical setting.

trial fibrillation affects about 350000 Canadians, with a prevalence heavily skewed toward higher age groups ${ }^{1,2}$ Anticoagulants required for the prevention of stroke in these patients eclipse all other drugs in their frequent and clinically significant benefit and harm: a March 2013 report by the Canadian Institute for Health Information highlighted anticoagulants as the drug class most commonly associated with hospitalizations in seniors due to adverse events from 2006 to 2011 . $^{3}$

Dabigatran and rivaroxaban have been approved for use in patients undergoing orthopedic surgery since 2008. The approval of novel oral anticoagulants for atrial fibrillation began in October 2010 with dabigatran, followed by rivaroxaban in January 2012 and apixaban in December 2012. ${ }^{4}$ The recommendation of their use as first-line therapy in the Canadian Cardiovascular Society guidelines represents an expansion of the clinical armamentarium for stroke prophylaxis. ${ }^{5}$
However, patients in real clinical settings often differ from participants of randomized trials used to inform the development of these guidelines. ${ }^{6} \mathrm{With}$ respect to novel oral anticoagulants, age is of particular interest given the increased risk of bleeding among older patients and the lack of an antidote..$^{7-10}$

We conducted this study to determine the prescribing patterns of oral anticoagulants in Ontario, Canada's largest province, since the arrival of novel oral anticoagulants. We focused on changes in prescription rates by age group.

Competing interests: See end of article for competing interests. This article has been peer reviewed.

Correspondence to: Ana P. Johnson, ana.johnson@queensu.ca

CMAJ Open 2013.DOI:10.9778/cmajo.20130032 


\section{OPEN}

Research

\section{Methods}

\section{Data collection}

We obtained data on dispensed medications for Ontario residents aged 20 years or more who filled prescriptions for an oral anticoagulant (warfarin, dabigatran or rivaroxaban) between October 2010 (when the first novel oral anticoagulant, dabigatran, was approved for use in atrial fibrillation) and September 2012. Aggregate monthly prescription volumes were acquired from IMS Brogan (Canadian CompuScript Audit), which collects prescription records from nearly twothirds of Canadian retail pharmacies regardless of payer type. These data are extrapolated to jurisdictional prescription volumes by means of standardized weighting methods and are used frequently to evaluate prescription trends. ${ }^{11-13}$

\section{Statistical analysis}

We used linear regression, accounting for first-order autoregressive residuals, to evaluate prescription trends in a timeseries analysis. When temporally sequenced data are used in regression analysis, often the error term is not independent through time, adversely biasing the standard error estimates. The autoregressive error model corrects for this serial correlation or autoregression. ${ }^{14}$

We calculated monthly prescriptions per 100000 population for all oral anticoagulants. Because rivaroxaban prescriptions accounted for only $3.9 \%$ of total prescriptions by the end of the study period, they were not included in subsequent analyses. We stratified dabigatran prescription rates by age group (20-39, 40 $59,60-64,65-84$ and $\geq 85$ years). Furthermore, using the $\chi^{2}$ test, we compared the percentage of dabigatran prescriptions filled by

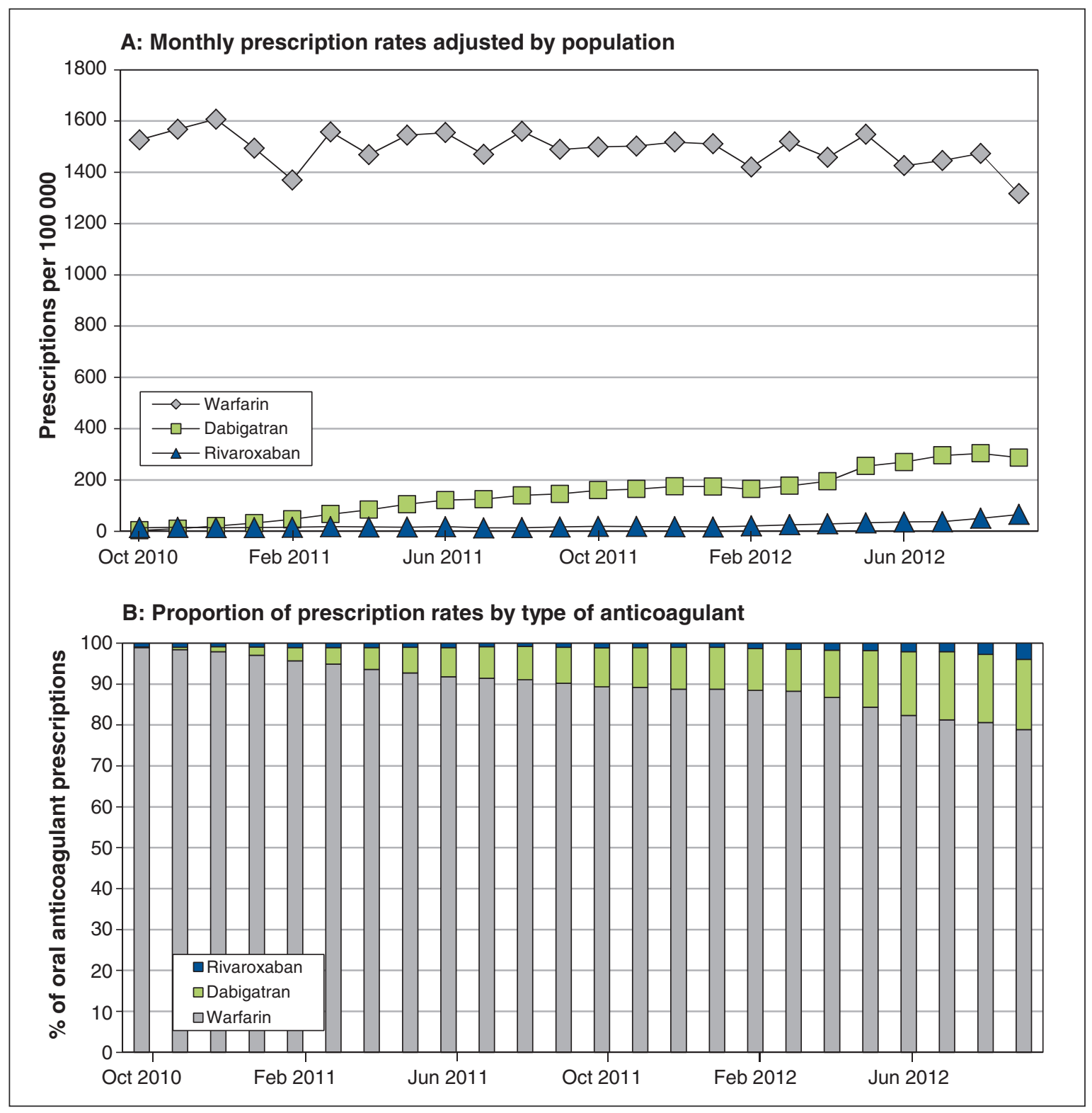

Figure 1: Monthly prescription rates for warfarin, dabigatran and rivaroxaban in Ontario among adults aged $\geq 20$, adjusted by population $(A)$ and proportion of prescription rates by type of anticoagulant (B). 
people aged 65 or older with similar data reported from the Randomized Evaluation of Long-Term Anticoagulation Therapy (RE-LY) study. ${ }^{15}$ A sensitivity analysis was also undertaken that evaluated only new prescriptions and excluded refill prescriptions. Population data were based on the 2011 Canadian census. ${ }^{16}$

\section{Results}

During the 24-month study period, monthly prescriptions of novel oral anticoagulants increased more than 20-fold, from 16 to 336 prescriptions per 100000 population. The change in prescribing patterns was due primarily to an increase in dabigatran use, which rose from 3 to 274 prescriptions per 100000 population $\left(p_{\text {trend }}<0.001\right.$; Figure 1A). By September 2012, dabigatran represented $17.2 \%$, and rivaroxaban $3.9 \%$, of all oral anticoagulant prescriptions (Figure 1B). Monthly prescriptions of warfarin over the study period decreased from 1526 to 1316 per $100000\left(p_{\text {trend }}=0.007\right)$.

Dabigatran prescription rates were highest among patients aged 85 or more, and next highest among those 65-84 years of age (Figure 2). Since April 2012, the proportion of dabigatran prescriptions filled by patients 65 or older exceeded the proportion of participants in the same age group enrolled in dabigatran arms of the RE-LY trial $(87.3 \%$ v. $83.2 \%, p<$ 0.001). In September 2012, most of the dabigatran prescriptions were for the lower dosage $(110 \mathrm{mg} / \mathrm{d})$ in the older groups in our study (58.8\% of prescriptions in the 65-84 age group and $93.6 \%$ in the oldest group).

When we restricted the analysis to new prescriptions of dabigatran, the trends by age group were similar to those in the main analysis (Appendix 1A, available at www.cmajopen.ca /content/1/3/E115/supp1/DC1). Although the rates of new prescriptions across age groups appeared to plateau over time, the relative distribution of new dabigatran prescriptions across age groups remained stable over time, with the largest proportion in the oldest group (Appendix 1B).

\section{Interpretation}

We found a rapid uptake of dabigatran in Ontario in the 24 months after its approval for atrial fibrillation, with onset preceding its coverage by the Ontario Public Drug Programs in April 2012. The rate of warfarin prescription declined with the rise in use of novel oral anticoagulants, and use of rivaroxaban did not increase substantially from baseline over the study period, even after its approval for use in atrial fibrillation in January 2012. We also observed that dabigatran was heavily prescribed to patients aged 85 or more, especially the lower-dose formulation.

Results of our study are consistent with those in 2 reports of prescription trends for novel oral anticoagulants. A nationally representative survey in the United States reported an increase in physician visits involving dabigatran prescription as a proportion of oral anticoagulants, from $3.1 \%$ in the fourth quarter of 2010 to $18.9 \%$ one year later. ${ }^{17}$ At end of the study period, $87 \%$ of dabigatran-related physician visits were by patients 65 or older. In New Zealand, the prevalence of dabigatran use among patients aged 80 and over was 1300 per 100000 population, and $80.1 \%$ of prescriptions were for patients 65 or older. $^{18}$

In keeping with the Canadian Cardiovascular Society guidelines first published in January 2011 and updated in April 2012, which recommend the use of novel oral anticoagulants over warfarin, ${ }^{5,19}$ dabigatran has been actively integrated into the care of patients with atrial fibrillation. Although novel oral anticoagulants represent an opportunity to improve anticoagulation uptake, the US Food and Drug Administration (FDA) noted that postmarketing use of dabigatran "might be different from its use in the RE-LY trial ... e.g., different patient populations. ${ }^{20}$ Our results corroborate this perspective: we found that prescription rates of dabigatran were most accelerated among patients 85 or older, a group at increased risk of bleeding who are markedly older than the average participant in the clinical trial in which the drug was tested $(71 \mathrm{yr}){ }^{21}$

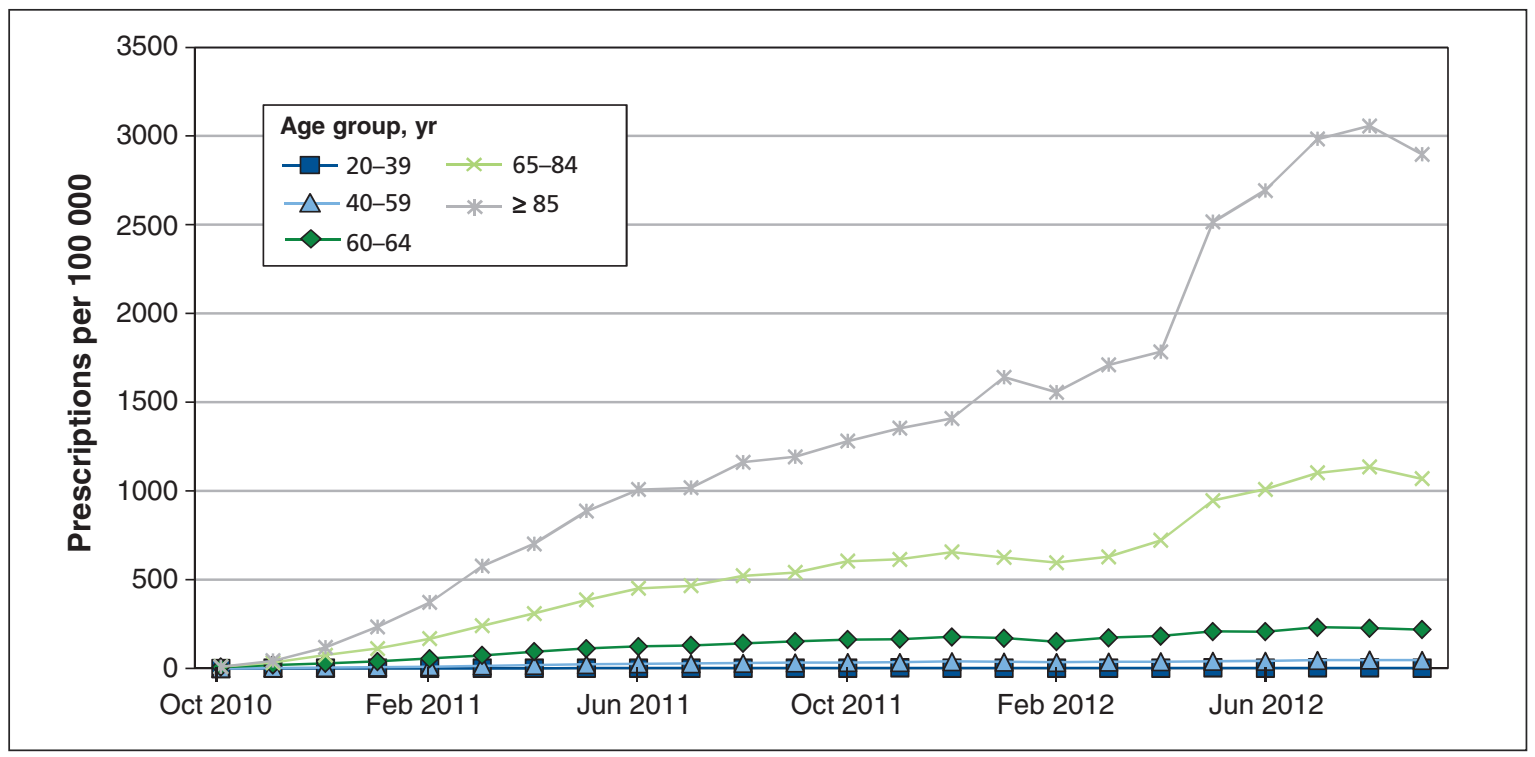

Figure 2: Age-stratified monthly prescription rates for dabigatran in Ontario among adults aged $\geq 20$, adjusted by population. 
In contrast to the overall RE-LY trial results, which suggested a lower risk of major bleeding with dabigatran $110 \mathrm{mg}$ than with warfarin, ${ }^{22}$ a recent network meta-analysis by the Canadian Agency for Drugs and Technologies in Health found comparable risks of major bleeding (the definition of which includes intracranial hemorrhage) among patients 75 years or older. ${ }^{23}$ This corroborates findings of a subgroup analysis involving RE-LY participants 80 or older submitted to the US FDA by the trial sponsor that showed equivalent risk of major bleeding with dabigatran $110 \mathrm{mg}$ (5.25\% per year) compared with warfarin $(4.70 \%$ per year). ${ }^{24}$ Because no effective reversal agent exists for dabigatran, ${ }^{9}$ this difference in safety outcomes between the overall RELY trial cohort and the subgroup experiencing the most rapid "real-world" uptake may have an unexpected impact in clinical practice as knowledge from the RE-LY trial is swiftly adopted.

\section{Limitations}

Our study has several limitations. First, the use of prescription volume rather than patient volume creates potential bias in cases of differential prescribing frequency. However, our results are comparable to those generated by patient-based methodologies ${ }^{17}$ and our analysis that was restricted to new prescriptions of dabigatran yielded trends similar to those of the main analysis.

Second, we were unable to stratify prescription volume by indication, and thus the data included prescriptions for novel oral anticoagulants in patients undergoing orthopedic surgery. However, their contribution to the overall prescription pattern was likely small: dabigatran and rivaroxaban have been approved for use in patients undergoing orthopedic surgery since 2008 , but prescriptions remained low until their approval for use in atrial fibrillation.

Finally, our study period for capturing data on prescriptions ended just as rivaroxaban prescribing for atrial fibrillation would have been starting and before apixaban was approved for use in atrial fibrillation.

\section{Conclusion}

We observed rapid growth in the uptake of the novel oral anticoagulants, in particular dabigatran within the 2 years after its approval for use in patients with atrial fibrillation. Although results of the RELY-ABLE study, which looked at the long-term effects of dabigatran in patients completing the RE-LY trial, suggest long-term safety and efficacy of dabigatran in the phase IV trial setting, ${ }^{25}$ growth in the uptake of novel oral anticoagulants in very old patients, a group at high risk of bleeding, signals the need to evaluate outcomes in clinical practice to better guide the use of these agents.

\section{References}

1. O'Reilly DJ, Hopkins RB, Healey JS, et al. The burden of atrial fibrillation on the hospital sector in Canada. Can $\mathcal{F}$ Cardiol 2013;29:229-35.

2. Go AS, Hylek EM, Phillips KA, et al. Prevalence of diagnosed atrial fibrillation in adults: national implications for rhythm management and stroke prevention: the An Ticoagulation and risk factors in atrial fibrillation (ATRIA) study. $7 A M A$ 2001;285:2370-5

3. Adverse drug reaction - related hospitalizations among seniors, 2006 to 2011. Ottawa (ON): Canadian Institute for Health Information; 2013. Available: https://secure.cihi.ca/free_products/Hospitalizations\%20for\%20ADR-ENweb.pdf (accessed 2013 May 13).
4. Drugs@FDA: FDA approved drug products. Silver Spring (MD): Food and Drug Administration. Available: www.accessdata.fda.gov/scripts/cder/drugsatfda/ (accessed 2013 Mar. 9)

5. Skanes AC, Healey JS, Cairns JA, et al. Focused 2012 update of the Canadian Cardiovascular Society atrial fibrillation guidelines: recommendations for stroke prevention and rate/rhythm control. Can 7 Cardiol 2012;28:125-36.

6. Nallamothu BK, Hayward RA, Bates ER. Beyond the randomized clinical trial: the role of effectiveness studies in evaluating cardiovascular therapies. Circulation 2008;118:1294-303

7. Beasley BN, Unger EF, Temple R. Anticoagulant options - why the FDA approved a higher but not a lower dose of dabigatran. N Engl 7 Med 2011;364: 1788-90.

8. Eikelboom JW, Wallentin L, Connolly SJ, et al. Risk of bleeding with 2 doses of dabigatran compared with warfarin in older and younger patients with atrial fibrillation: an analysis of the randomized evaluation of long-term anticoagulant therapy (RE-LY) trial. Circulation 2011;123:2363-72.

9. Legrand M, Mateo J, Aribaud A, et al. The use of dabigatran in elderly patients. Arch Intern Med 2011;171:1285-6.

10. Harper P, Young L, Merriman E. Bleeding risk with dabigatran in the frail elderly. N Engl f Med 2012;366:864-6.

11. Dhalla IA, Mamdani MM, Sivilotti ML, et al. Prescribing of opioid analgesics and related mortality before and after the introduction of long-acting oxycodone. CMA7 2009;181:891-6.

12. Juurlink DN, Mamdani MM, Lee DS, et al. Rates of hyperkalemia after publication of the randomized aldactone evaluation study. N Engl 7 Med;351:543-51.

13. Majumdar SR, McAlister FA, Soumerai SB. Synergy between publication and promotion: comparing adoption of new evidence in Canada and the United States. Am 7 Med 2003;115:467-72.

14. SAS/ETS ${ }^{\circledR} 9.2$ user's guide. Cary (NC): SAS Institute Inc.; 2008.

15. Pradaxa (dabigatran) [clinical review], NDA 22-512 [Table 22]. Silver Spring (MD): US Food and Drug Administration; 2010. Available: www.fda.gov/downloads /AdvisoryCommittees/CommitteesMeetingMaterials/Drugs/Cardiovascularand RenalDrugsAdvisoryCommittee/UCM247244.pdf (accessed 2013 Feb. 16).

16. Census profile: 2011 census. Ontario (Code 35) and Canada (Code 01) [table]. Ottawa (ON): Statistics Canada; 2012. Cat. no. 98-316-XWE.

17. Kirley K, Qato DM, Kornfield R, et al. National trends in oral anticoagulant use in the United States, 2007 to 2011. Circ Cardiovasc Qual Outcomes 2012;5:615-21.

18. Metcalfe S, Moodie P. National prescribing data for dabigatran. NZ Med 72012 ; 125:97-105.

19. Cairns JA, Connolly S, McMurtry S, et al.; CCS Atrial Fibrillation Guidelines Committee. Canadian Cardiovascular Society atrial fibrillation guidelines 2010: prevention of stroke and systemic thromboembolism in atrial fibrillation and flutter. Can 7 Cardiol 2011;27:74-90.

20. Southworth MR, Reichman ME, Unger EF. Dabigatran and postmarketing reports of bleeding. N Engl 7 Med 2013;368:1272-4.

21. Connolly SJ, Ezekowitz MD, Yusuf S, et al. Dabigatran versus warfarin in patients with atrial fibrillation. N Engl F Med 2009;361:1139-51.

22. Connolly SJ, Ezekowitz MD, Yusuf S, et al.; Randomized Evaluation of LongTerm Anticoagulation Therapy Investigators. Newly identified events in the RE-LY trial. N Engl 7 Med 2010;363:1875-6.

23. Antithrombotic agents for the prevention of stroke and systemic embolism in patients with atrial fibrillation [Table A13.10]. Ottawa (ON): Canadian Agency for Drugs and Technologies in Health; 2013. Available: www.cadth.ca/media /pdf/TR0003_AntithromboticAgents-AF_ScienceReport_e.pdf (accessed 2013 Mar. 31).

24. Boehringer Ingelheim dabigatran briefing information: dabigatran etexilate mesylate capsules [Table 7.3.1:8]. Silver Spring (MD): Food and Drug Administration; 2010. Available: www.fda.gov/downloads/AdvisoryCommittees/Committees MeetingMaterials/Drugs/CardiovascularandRenalDrugsAdvisoryCommittee /UCM226009.pdf (accessed 2013 Feb. 16).

25. Connolly SJ, Reilly PA, Pogue J, et al. Randomized comparison of the effects of two doses of dabigatran etexilate on clinical outcomes over 4.3 years: results of the Rely-Able double-blind randomized trial [abstract]. Circulation 2012; $126: 2793$.

Competing interests: Christopher Simpson reports receiving speaker fees from Boehringer Ingelheim and Bayer Canada, and serving on an advisory board for Bristol-Myers Squibb. Dar Dowlatshahi reports receiving travel and speaker honoraria from Boehringer Ingelheim and has served on advisory boards for Bayer Canada, Bristol-Myers Squibb and Pfizer. No competing interests declared by Yan $\mathrm{Xu}$, Anne Holbrook and Ana Johnson.

Affiliations: School of Medicine (Xu), Division of Cardiology, Department of Medicine (Simpson), and Department of Population Health Sciences (Johnson), Queen's University, Kingston, Ont.; Division of Clinical Pharmacology and Therapeutics, Department of Medicine (Holbrook), McMaster University, Hamilton, Ont.; Division of Neurology, Department of Medicine, and the Ottawa Hospital Research Institute (Dowlatshahi), University of Ottawa, Ottawa, Ont. 
Contributors: Yan Xu contributed to conception and design of the study. Yan $\mathrm{Xu}$ and Ana Johnson acquired the data. Yan Xu was involved in data analysis, and all authors contributed to data interpretation. Yan Xu drafted the manuscript, which all of the authors provided revisions for important intellectual content. All of the authors approved the final version submitted for publication.

Funding: This study was funded by the Canadian Institutes of Health Research — Drug Safety and Effectiveness Network (grant no. PAS 126297).

Acknowledgements: The authors are grateful to IMS Brogan for providing prescribing data, and Andrew Day at the Kingston General Hospital Clinical
Research Centre for assistance with statistical analysis. Yan Xu is supported by a studentship from the Heart and Stroke Foundation of Ontario as well as the Ontario Drug Policy Research Network; the latter is funded by a grant from the Ontario Ministry of Health and Long-Term Care Drug Innovation Fund. The opinions, results and conclusions reported in this paper are those of the authors and are independent from sources of funding or data. No endorsement by the Ontario Ministry of Health and LongTerm Care or IMS Brogan is intended or should be inferred.

Supplemental information: For reviewer comments and the original submission of this manuscript, please see at www.cmajopen.ca/content /1/3/E115/suppl/DC1 